\title{
A Study Depicting Histomorphology of Third Trimester Placenta in SARS-Cov-2 Positive Women
}

\author{
Neelanjali Jain*, Reeni Malik and Sharda Balani \\ Department of Pathology, Gandhi Medical College, Bhopal
}

\begin{abstract}
Background: This study aims to detect association of SARS-COV-2 infection in terms of histopathological changes in the third trimester placenta.

Methods: SARS COV 2 positive placenta cases received in Department of Pathology, Gandhi Medical College and Hamidia Hospital, Bhopal, Madhya Pradesh. 7 cases were sent for histopathological examination. Clinical details, history, details of relevant investigation like D-dimer, blood reports etc. was taken from the electronic medical records and requisition form received in the Department of Pathology. Histopathological findings were analyzed and recorded.

Result: This is a case series depicting various histopathological changes in term placenta of 7 SARS Corona Virus 2 (COV-2) positive women in the age group of 20 years to 35 years exhibiting symptoms ranging from mild to severe degree. The major histopathological finding noticed is under perfusion of placenta of maternal side in greater extent as compared to fetal side under perfusion followed by signs of inflammation of membranes viz chorionitis and chorioamnionitis. Hence, through the study, we want to highlight micro vasculopathy as one of the pathophysiological features of SARS Corona Virus 2 (COV-2) which might be leading to these histopathological findings and its correlation with elevated levels of D - Dimer.
\end{abstract}

Conclusion: Covid 19 positive women with third trimester of placenta do not express any specific histomorphological findings. Our study shows only signs of maternal and fetal vascular under perfusion with mild acute chorionitis which might have a relationship to a microvascular disease induced by SARS COVID 19 virus, yet this cannot be ruled out consistently proven several associated factors.

Keywords: SARS-Cov-2, Third Trimester, Placenta, Histomorphological Changes

\section{Introduction}

With the recent pandemic of Coronavirus infection within a few months, hospitals can expect an influx of large numbers of Covid-19 positive cases. Coronavirus disease 2019 (COVID -19) is caused by SARS Corona virus 2, belongs to beta coronavirus family. ${ }^{1}$ SARS-Cov-2 is an enveloped, single stranded RNA virus and it's composed of four structural proteins (Spike surface glycoprotein, envelop protein, membrane protein and nucleocapsid protein) and non -structural protein. ${ }^{2}$ Studies showed that the spike protein of this virus binds to angiotensin converting enzyme 2 (ACE 2), which is a functional receptor for SARS Cov2 ${ }^{3}$. The ACE expression receptor is high in lung, kidney, heart and ileum, so it primarily affects the respiratory system. The Placenta is the key organ at maternal / fetal interface and essentially function as the lungs and kidney for the fetus in utero. ${ }^{4}$ Recent studies suggested that SARS Cov2 can access the placental interface and potentially be transmitted to the foetus 5 . Studies have already analyzed the gross and histopathology of placenta in COVID -19 and would describe micro-vasculopathy and inflammatory response was rarely found.
We present a case series of six placentas of SARS-Cov2 positive women who had been diagnosed corona infection by RT-PCR before birth of baby. We provided a detailed histopathological finding of morphological changes in presence of SARS - CoV-2 infection in placental tissue.

\section{Materials and Methods}

SARS COV 2 positive placenta cases received in the Department of Pathology at Gandhi Medical College, Bhopal and consisted of 7 cases have been sent for histopathological examination. To prevent infection, tissue was fixed for 48 hours then processed according to standard procedures. After fixation grossing was done with three sections of placental tissue as well as one section from the umbilical cord and chorionic membranes. These sections were processed into paraffin blocks and stained with Hematoxylin and Eosin stain. All mothers were tested positive via RT-PCR at Gandhi Medical College, Bhopal. Histopathological finding, according to Current Amsterdam Placental Workshop Group Consensus statement. Clinical information was taken from the electronic medical records, which given in Table 1. 


\section{Result}

We enrolled 7 pregnant patients who were tested positive (both symptomatic and asymptomatic) for covid 19. All placenta were term deliveries $\left(37^{\text {th }}\right.$ to $39^{\text {th }}$ gestational weeks). The age of the patients ranged between 20 years to 35 years. 2 patients presented with mild symptoms (case 2, 4\& 7) fever, cough and dyspnea and other 4 cases were asymptomatic prior to delivery and in postpartum period also. All patients were delivered by caesarean section. Clinical and biochemical findings are summarized in table 1 . Two patients (case $1 \& 3$ ) had a past history of hypothyroidism and oligohydramnios respectively. All infants were healthy \& tested negative for COVID 19 by RT-PCR testing.

Histopathological findings are summarized in table 2 . Diagnosis was made and graded using Current classification (Amsterdam system)

\begin{tabular}{|l|l|}
\hline 1. Maternal uterine / & 3. Inflammation, infectious \\
trophoblastic & Acute: \\
\hline Daldevelopment: & Chorioamnionitis \\
Superficial implantation & Villitis \\
Malperfusion: & Intervillositis \\
Partial global: Accelerated & Chronic (TORCH) \\
villous maturation & Villitis \\
Complete segmental: & Intervillositis \\
Infarct, Infarction- & Deciduitis \\
hematoma & \\
Loss integrity: & \\
Abruptio placenta & \\
Marginal abruption, acute & \\
or chronic & \\
\hline 2. Fetal stromal-vascular & 4. Inflammatory, Idiopathic \\
\hline Maldevelopment: & Villitis/VUE \\
Delayed villous maturation & Chronic deciduitis \\
Villous capillary lesions & Fetal vasculitis, \\
Malperfusion: & eosinophilic T cell \\
Partial global: umbilical & Intervillositis, histiocytic \\
cord compromise & 5. Pathogenesis \\
Complete segmental: fetal & incompletely understood \\
thrombosis & Perivillous fibrin deposition, \\
Loss of integrity: & diffuse or localized \\
Small vessel hemorrhage & 6.Other \\
Large vessel hemorrhage & Malformation \\
Oedema & Tumors and heterotopias \\
Secondary / Extrinsic & Morbidly adherent placenta \\
Meconium effects & Genetic / chromosomal \\
Increased nucleated red & abnormalities \\
cells (NRBC) & \\
\hline
\end{tabular}

\section{Findings of placenta with COVID 19}

Out of 7 cases feto-maternal vascular under perfusion was seen in 2 cases (28.5\%) and maternal vascular under perfusion was seen in the rest of the 5 cases $(71.4 \%)$. In our study all placenta revealed term villi, there was no accelerated villous maturation seen. 3 Cases (2,4 \& 6) $(42.8 \%)$ showed increased syncytial knot formation. Signs of maternal vascular under-perfusion such as, infarction (not seen in our study), increased peri-villous fibrin deposition (seen in 4 cases) $57.1 \%$, fibrinoid necrosis (seen in 5 cases) $71.4 \%$, calcification (seen in 4 cases) $57.1 \%$, retro-placental hemorrhage and inter-villous thrombosis (not seen in our study), were studied. Signs of fetal underperfusion like thrombi in fetal circulation and chorangiosis were seen in case $(1,4)$ and case 4 respectively. Other signs such as fibrinoid necrosis, calcification, thrombi in fetal circulation, villous maturation, retroplacental hemorrhage, intervillous thrombosis, deciduitis \& fetal vasculitis were absent in all other cases.

Signs of inflammation of placental membranes as chorionitis, chorioamnionitis were predominantly noted in $42.8 \%$ cases $(2,3 \& 5)$. One case (3), in which patient had cough, fever and oligohydramnios and fetal distress showed evidence of both acute chorionitis and chorioamnionitis possibly because of ascending infections.

\section{Discussion}

The effects of covid-19 in pregnant women and neonates are relatively unknown. Previous studies have studied the association of covid-19 with micro-vasculopathy, manifesting as maternal vascular under perfusion and fetal under perfusion. ${ }^{6}$

In our study we found both maternal and fetal under perfusion in only one case $(14.2 \%)$ (case 1$)$, although it's effect on fetal and maternal health were insignificant, however 5 cases showed signs of maternal under perfusion. This suggests that effects of SARS covid-19 are prominent in mother and fetus are relatively unaffected due to maternal infection. Rebecca N Baergen and Debra S Heller [2020] have demonstrated furcated placenta in covid - 19 pregnant women, suggesting maternal covid 19 infections associated with a tendency of thrombi formation in fetal circulation. However, in our study no gross abnormality was found in terms of umbilical cord insertion (marginal insertion being normal) ${ }^{7}$. A study can be done in patients who were tested positive in first trimester in order to study in detail the mal insertion due to covid-19.

Asim Kichloo, Kirk Dettloff et. al Oct 2020 stated that COVID 19 has an association with hyper-coagulability because of elevation of D-dimmer and it manifest as development of hypoxia induced ischemic changes and disseminated intravascular coagulopathy in one series. This goes in agreement with our findings of elevated DDIMER values in 2 cases $(28.5 \%){ }^{8}$ In that case we found 
Tables: Clinical and biochemical findings in Covid 19 positive women (Table 1).

\begin{tabular}{|l|l|l|l|l|l|l|l|}
\hline & Patient 1 & Patient 2 & Patient 3 & Patient 4 & Patient 5 & Patient 6 & Patient 7 \\
\hline Age at birth, yrs & $30 \mathrm{yr}$ & $23 \mathrm{yr}$ & $25 \mathrm{yr}$ & 28yr & $33 \mathrm{yr}$ & $43 \mathrm{yr}$ & $26 \mathrm{yr}$ \\
\hline Gestational week & $38 \mathrm{wks}+5 \mathrm{~d}$ & $38 \mathrm{wks}$ & $36 \mathrm{wks}+2 \mathrm{~d}$ & $37 \mathrm{wk}+4 \mathrm{~d}$ & $39 \mathrm{wk}+1 \mathrm{~d}$ & $39 \mathrm{wks}$ & $38 \mathrm{wks}$ \\
\hline Types of birth & CS & CS & CS & CS & CS & CS & CS \\
\hline Gravida/Para & G1P0 & G2P1L1 & G1P1A0 & G3P1A1L1 & G1P0A0 & G2P1A0 & G1P0A0 \\
\hline $\begin{array}{l}\text { SARS CoV2 test } \\
\text { positive prior to birth }\end{array}$ & 2days & 1days & 1days & 3days & 1 day & 2 days & 4 days \\
\hline $\begin{array}{l}\text { Covid 19 related } \\
\text { symptoms }\end{array}$ & None & $\begin{array}{l}\text { Mild } \\
\text { cough, } \\
\text { fever }\end{array}$ & Cough \& fever & $\begin{array}{l}\text { Mild } \\
\text { cough, } \\
\text { fever }\end{array}$ & None & None & $\begin{array}{l}\text { Fever, } \\
\text { cough }\end{array}$ \\
\hline Past medical history & Hypothyroidism & None & None & None & None & None & None \\
\hline $\begin{array}{l}\text { Pregnancy related } \\
\text { complication }\end{array}$ & Fetal distress & - & $\begin{array}{l}\text { Oligohydramnios, } \\
\text { fetal distress }\end{array}$ & None & None & None & None \\
\hline D-dimer (0-500 ng/mI) & 1.06 & 245 & 245 & 734 & 300 \\
\hline
\end{tabular}

Table 2: Histopathological findings.

\begin{tabular}{|c|c|c|c|c|c|c|c|c|}
\hline & Case 1 & Case 2 & Case 3 & Case 4 & Case 5 & Case 6 & Case 7 & Remarks \\
\hline Placental weight, g & 539 & 544 & 529 & 589 & 531 & 603 & 590 & n.a. \\
\hline Term villi & + & + & + & + & + & + & & n.a. \\
\hline Syncytial knot & - & + & - & - & + & ++ & + & n.a. \\
\hline \multicolumn{9}{|c|}{ Signs of maternal malperfusion } \\
\hline 1. Infarction & - & - & - & - & - & - & & \\
\hline $\begin{array}{l}\text { 2.Increased perivillous fibrin } \\
\text { deposition }\end{array}$ & + & + & ++ & - & - & + & - & $0 / 7$ \\
\hline 3. Fibrinoid necrosis & + & + & + & - & + & + & + & $4 / 7$ \\
\hline 4. Calcification & + & + & - & - & + & + & + & $5 / 7$ \\
\hline 5.Retroplancetal hemorrhage & - & - & - & - & - & - & & $4 / 7$ \\
\hline 6. Intervillous thrombosis & - & - & - & - & - & - & & $0 / 7$ \\
\hline \multicolumn{9}{|c|}{ Signs of fetal malperfusion } \\
\hline $\begin{array}{l}\text { 1. Thrombi in the fetal } \\
\text { circulation }\end{array}$ & + & - & - & + & - & - & - & $2 / 7$ \\
\hline 2. Avascular villi & - & - & - & - & - & - & & $0 / 7$ \\
\hline 3. Karyorrhexis & - & - & - & - & - & - & & $0 / 7$ \\
\hline $\begin{array}{l}\text { 4. Delayed villous maturation } \\
5 . \text { Chorangiosis }\end{array}$ & - & - & - & + & $\begin{array}{l}- \\
-\end{array}$ & - & - & $\begin{array}{l}0 / 7 \\
1 / 7\end{array}$ \\
\hline \multicolumn{9}{|c|}{ Inflammatory changes } \\
\hline Chorioamnionitis & - & - & + & - & - & - & & $1 / 7$ \\
\hline Chronic villitis & - & - & - & - & - & - & - & $0 / 7$ \\
\hline $\begin{array}{l}\text { Chronic deciduitis } \\
\text { chorionitis }\end{array}$ & - & - & - & - & - & - & - & $0 / 7$ \\
\hline
\end{tabular}




\begin{tabular}{|l|l|l|l|l|l|l|l|l|}
\hline & Case 1 & Case 2 & Case 3 & Case 4 & Case 5 & Case 6 & Case 7 & Remarks \\
\hline Choriovasculitis & - & + & + & - & + & - & - & $3 / 7$ \\
\hline Fetal vasculitis & - & - & - & - & - & - & & $0 / 7$ \\
\hline Placenta accrete & - & - & - & - & - & - & & $0 / 7$ \\
\hline $\begin{array}{l}\text { Marginal insertion of the } \\
\text { umbilical cord }\end{array}$ & - & - & - & - & - & - & - & $0 / 7$ \\
\hline Hyper coiling of umbilical cord & - & - & - & - & - & - & - & n.a. \\
\hline Phagocytosis of meconium & - & - & - & - & - & - & - & n.a. \\
\hline Diffuse villous edema & - & - & - & - & - & - & - & n.a. \\
\hline $\begin{array}{l}\text { Umbilical cord } \\
\text { (2 Artery and 1 vein) }\end{array}$ & + & + & + & + & + & + & + & $\begin{array}{l}\text { No } \\
\text { abnormality }\end{array}$ \\
\hline
\end{tabular}
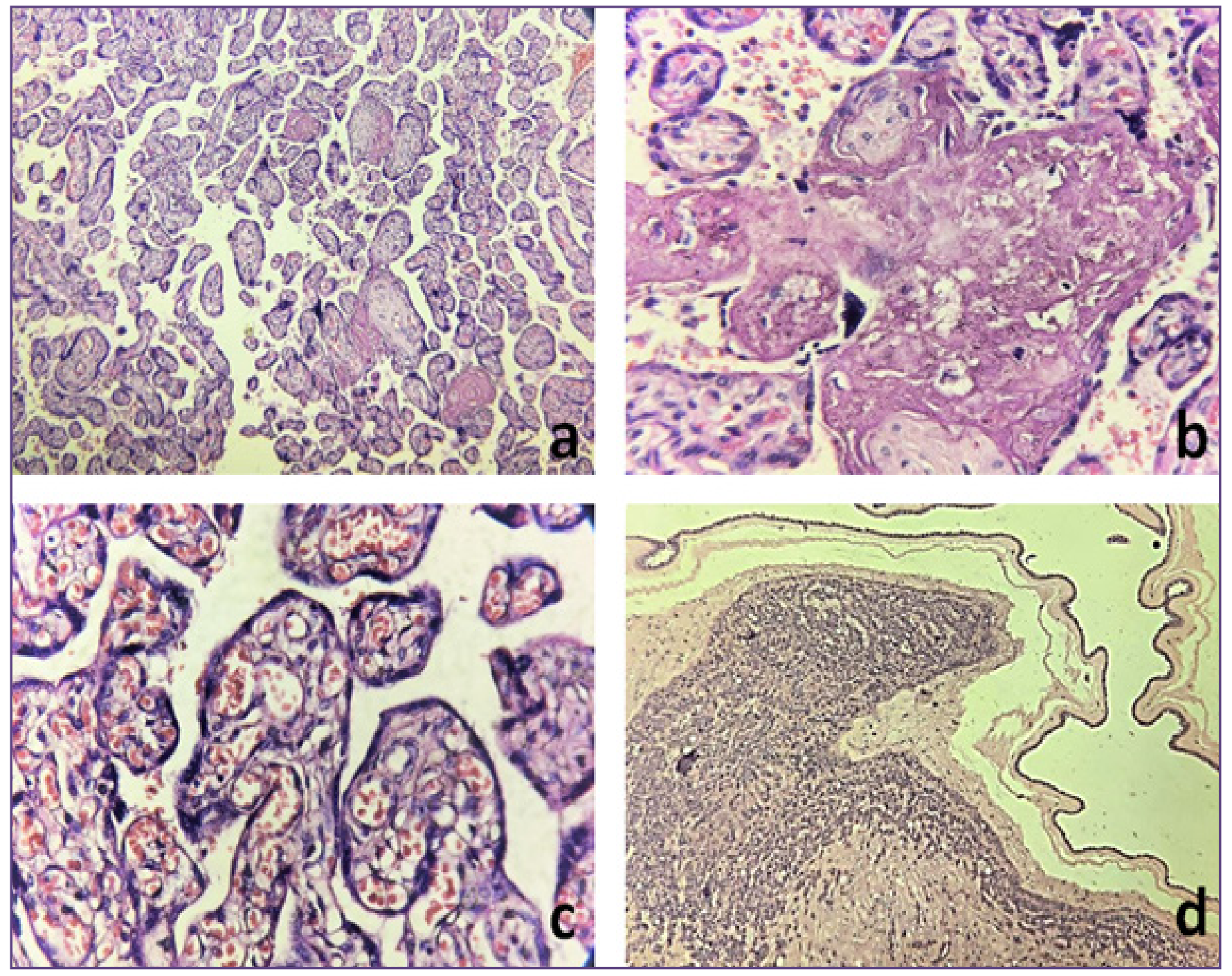

Fig. 1: Findings of placenta with COVID 19 a. Macroscopic image showing placental parenchyma b. Increased intervillous fibrin deposition as a sign of maternal malperfusion C. Chorangiosis, sign of fetal malperfusion (40x) d. Chorioamnionitis (40x). 
increase perivillous fibrin deposition, fibrinoid necrosis and chorionitis.

Shanes et al. May 2020, investigated 16 COVID 19 positive cases showing signs of feto-maternal malperfusion. Among them only 2 cases $(28.5 \%)$ showed chronic villitis. Signs of inflammation of placental membranes as chorionitis, chorioamnionitis were predominantly noted in $42.8 \%$ cases $(2,3 \& 5)$ in our study. One symptomatic patient with complicated pregnancy and signs of fetal distress showed evidence of both acute chorionitis and chorioamnionitis possibly because of ascending infections, not attributable to covid-19.

The confounding factors like hypertension, diabetes mellitus and obesity should be considered before attributing such changes for SARS covid -19. In our study we enrolled patients without any such comorbidities and we didn't find changes which were seen in other studies. Pregnancy anyways is a hypercoagulable state, so further studies are needed to attribute these findings to covid-19. At present we don't have sufficient evidence to comment on the impact of covid-19 on placenta and thus on fetal health.

\section{Conclusion}

To conclude, Covid 19 positive women in third trimester of placenta do not express any specific histomorphological findings. Our study shows only signs of maternal and fetal vascular under perfusion with mild acute chorionitis which might have a relationship to a microvascular disease induced by Corona 2 virus, yet this cannot be ruled out consistently proven several associated factors. We do not rule out the impact of corona virus infection in early pregnancy.

\section{Acknowledgements}

We are thankful to Dr Reeni Malik, Prof. \& Head Dept of Pathology GMC, Bhopal \& Prof. Dr R.K. Nigam for providing technical help, writing assistance \& general support for the research. Thanks to all the faculty of Department of Pathology GMC, Bhopal.

\section{Funding}

Department of Pathology, Gandhi Medical College, Bhopal, M. P

\section{Competing Interests}

None

\section{Reference}

1. Petrilli CM, Jones SA, Yang J, Rajagopalan H, et al. Factors associated with hospital admission and critical illness among 5279 people with coronavirus disease 2019 in New York City: prospective cohort study. BMJ. 2020 May 22;369:m1966.

2. Mousavizadeh L, Ghasemi S. Genotype and phenotype of COVID-19: Their roles in pathogenesis [published online ahead of print, 2020 Mar 31]. J Microbiol Immunol Infect. 2020.

3. Xu, H., Zhong, L., Deng, J. et al. High expression of ACE2 receptor of 2019-nCoV on the epithelial cells of oral mucosa. Int J Oral Sci 12, 8 (2020).

4. Ho, D., Leong, J.W., Crew, R.C. et al. Maternal-placentalfetal biodistribution of multimodal polymeric nanoparticles in a pregnant rat model in mid and late gestation. Sci Rep 7, 2866 (2017).

5. Fenizia, C., Biasin, M., Cetin, I. et al. Analysis of SARSCoV-2 vertical transmission during pregnancy. Nat Commun 11, 5128 (2020).

6. Egloff C, Vauloup-Fellous C, Picone O, Mandelbrot L, Roques $\mathrm{P}$. Evidence and possible mechanisms of rare maternal-fetal transmission of SARS-CoV-2. J Clin Virol. 2020 Jul; 128:104447

7. Baergen RN, Heller DS. Placental Pathology in Covid-19 Positive Mothers: Preliminary Findings. Pediatr Dev Pathol. 2020 May-Jun;23(3):177-180.

8. Kichloo A, Dettloff K, Aljadah M, et al. COVID-19 and Hypercoagulability: A Review. Clin Appl Thromb Hemost. 2020;26:1076029620962853.

9. Elisheva D Shanes, MD, Leena B Mithal, MD, MSCI, Sebastian Otero, Hooman A Azad, Emily S Miller, MD, MPH, Jeffery A Goldstein, MD, PhD, Placental Pathology in COVID-19, American Journal of Clinical Pathology, Volume 154, Issue 1, July 2020.

*Corresponding author:

Dr. Neelanjali Jain, H block girls hostel Gandhi Medical College Bhopal, PIN - 462001

Phone: +918233532271

Email: nkesar000@gmail.com

Date of Submission $\quad: 21 / 05 / 2021$

Date of Final Revision : 21/06/2021

Date of Acceptance $\quad$ : 28/06/2021

Financial or other Competing Interests: None.

Date of Publication : $\quad 30 / 08 / 2021$ 